\title{
Discrepancy between functional exercise capacity and daily physical activity: a cross-sectional study in patients with mild to moderate COPD
}

\section{*Annemieke Fastenau', Onno CP van Schayck1, Rik Gosselink², Karin CPM Aretz', Jean WM Muris'}

' Maastricht University Medical Centre, Department of Family Medicine, CAPHRI School for Public Health and Primary Care, Maastricht, The Netherlands

${ }^{2}$ KU Leuven, Faculty of Kinesiology and Rehabilitation Sciences, Leuven, Belgium

Originally received 14th May 2013; resubmitted 25th July 2013; revised 20th September 2013; accepted 22nd September 2013; online 11 th November 2013

\begin{abstract}
Background: In patients with moderate to severe chronic obstructive pulmonary disease (COPD) the six-minute walk distance reflects the functional exercise level for daily physical activity. It is unknown if this also applies to patients with mild to moderate COPD in primary care.

Aims: To assess the relationship between functional exercise capacity and physical activity in patients with mild to moderate COPD. Methods: A cross-sectional study was performed in 51 patients with mild to moderate COPD in primary care. Functional exercise capacity was assessed by the six-minute walk test and physical activity was measured with an accelerometer-based activity monitor.

Results: Functional exercise capacity was close to normal values. However, the daily physical activity of the patients could be classified as 'sedentary' and 'low active'. No significant correlations were observed between six-minute walk distance (\% predicted) and any of the physical activity variables (steps per day, movement intensity during walking, total active time, total walking time, physical activity level, and time spent in moderate physical activity).

Conclusions: A discrepancy was found between functional exercise capacity and daily physical activity in patients with mild to moderate COPD recruited and assessed in primary care. We conclude that these variables represent two different concepts. Our results reinforce the importance of measuring daily physical activity in order to fine-tune treatment (i.e. focusing on enhancement of exercise capacity or behavioural change, or both).

(C) 2013 Primary Care Respiratory Society UK. All rights reserved.

A Fastenau et al. Prim Care Respir J 2013; 22(4): 425-430

http://dx.doi.org/10.4104/pcrj.2013.00090
\end{abstract}

Keywords COPD, exercise capacity, physical activity, six-minute walk test, activity monitor, primary care, cross-sectional study

\section{See linked editorial by Troosters on pg 391}

\section{Introduction}

Chronic obstructive pulmonary disease (COPD) is a chronic disease characterised by poorly reversible airflow limitation. However, it is now recognised as a systemic illness with significant extrapulmonary features such as muscle wasting and weakness. ${ }^{1}$ In most patients shortness of breath during exercise is the first major symptom. To avoid confrontation with this symptom, patients with COPD are more inclined to adapt their lifestyle and thus a vicious circle will be created: shortness of breath results in decreased activity, which provokes a decline in exercise capacity and muscle strength, which in turn leads to more shortness of breath, and so on.

Exercise training programmes have been shown to be very effective in improving exercise capacity, ${ }^{2}$ so it is not surprising that most rehabilitation training programmes for patients with COPD focus on increasing exercise capacity. Functional exercise capacity reflects what a person is capable of doing under controlled circumstances in a laboratory setting. ${ }^{3}$ Another modifiable extrapulmonary feature of COPD is the decline in daily physical

\footnotetext{
* Corresponding author: Miss Annemieke Fastenau, Maastricht University Medical Centre, Department of Family Medicine, PO Box 616, 6200 MD Maastricht, The Netherlands. Tel: +31433882836 E-mail: annemieke.fastenau@maastrichtuniversity.nl.
} 
activity. Physical activity is defined as 'any bodily movement that is produced by the contraction of skeletal muscle and that substantially increases energy expenditure'. ${ }^{4}$ The dimensions of physical activity are: type, intensity, frequency, duration, and the context of the activity. Physical activity reflects what a person actually does on a regular basis. In the last decade, with the development of activity monitors, there is much more insight into physical activity levels in patients with COPD. As a result, we are now aware that what people with COPD are capable of doing might be different from what people actually do. ${ }^{5}$

Recent studies have shown that the physical activity level gradually declines with the severity of the disease ${ }^{6-8}$ and is the strongest predictor of all-cause mortality. ${ }^{9}$ Low levels of physical activity have been associated with systemic inflammation, left cardiac dysfunction, ${ }^{10}$ lung function decline, hospitalisations, and mortality. ${ }^{11}$ A review by $\mathrm{Ng}$ et al. suggests that the effect of exercise training on physical activity in people with COPD is small. ${ }^{12}$ Findings of more recent intervention studies show that improved exercise capacity after pulmonary rehabilitation (PR) is not transmitted into increased daily physical activity. ${ }^{13-16}$

Most of the studies concerning physical activity levels of patients with COPD are performed in patients with moderate to severe COPD who are recruited in a rehabilitation setting or an outpatient clinic. From these studies it is known that COPD patients are very inactive in daily life. A moderate relationship between exercise capacity and physical activity was observed, so that the six-minute walk test (6MWT) can be validated as a test to reflect functional exercise level for daily physical activity. ${ }^{6,17,18}$ However, in patients with a higher sixminute walk distance (6MWD), physical activities in daily life are highly variable, non-predictable, and require objective measurement. ${ }^{6}$

Although the majority of patients with COPD are classified as having mild to moderate disease, ${ }^{19}$ little is known about the relationship between functional exercise capacity and daily physical activity in these patients. We hypothesise that exercise capacity and daily physical activity are two different concepts in this patient category, as opposed to those with moderate to severe COPD. We therefore investigated the relationship between functional exercise capacity and physical activity.

\section{Methods}

\section{Study population}

In this cross-sectional study, a sample of 51 patients with mild to moderate COPD was recruited in 20 general practices in the southern part of the Netherlands. These patients were referred by their general practitioner or practice nurse to participate in a physical exercise COPD training programme at a local physiotherapy practice. Inclusion was based on symptoms of dyspnoea, impairments in exercise capacity, and a low level of self-reported physical activity.

Patients were in a stable condition and had not suffered from respiratory tract infections or exacerbations for at least 8 weeks prior to participation in the study. Subjects could participate if they had no significant co-morbid conditions that would impede the ability to improve physical activity such as severe cardiac failure, orthopaedic or neurological disorders.
All patients provided written informed consent and the study was approved by the ethical review board of the Maastricht University Medical Centre.

\section{Clinical, functional, and patient-reported characteristics}

All patients performed standardised post-bronchodilator spirometry according to the guidelines of the American Thoracic Society (ATS) and the European Respiratory Society (ERS). ${ }^{20}$ All had a forced expiratory volume in one second and forced vital capacity ratio $\left(\mathrm{FEV}_{1} / \mathrm{FVC}\right)<0.7$ and a post-bronchodilator $\mathrm{FEV}_{1}$ of $\geq 50 \%$ of predicted.

Functional exercise capacity was assessed by the 6MWT with reference values from Enright. ${ }^{21}$ The test was conducted according to the ATS guidelines ${ }^{22}$ except that a standard 30 metre corridor was not always feasible, but the minimal length of the corridor was 10 metres. Dyspnoea was assessed by the Medical Research Council (MRC) dyspnoea scale. ${ }^{23}$

\section{Physical activity assessment}

Daily physical activity was measured during three days and nights with an accelerometer-based activity monitor (Dynaport Minimod, McRoberts BV). Prior to the measurement the patient was asked if he/she had different physical activity patterns during weekdays or weekends. If the answer was no, then it did not matter on which days the measurement occurred. If the answer was yes, at least one weekday and one day of the weekend was included in the measurement. We later verified if the measurement days were representative. If the answer was negative, the measurement was repeated.

The Dynaport Minimod is among three of the best activity monitors to assess daily physical activity in patients with COPD..$^{24}$ As we were interested in the relationship between walking capacity and daily physical activity, we particularly collected walking-related data of physical activity including average steps per day, average movement intensity during walking, and total walking time per day. We also gathered more general information about physical activity such as total active time per day, time spent in moderate intense physical activities, and vigorous activities and physical activity level (PAL).

PAL was calculated by dividing a person's total energy expenditure by his/her basal metabolic rate. ${ }^{25} \mathrm{~A}$ PAL of $<1.40$ indicates a very inactive person and a PAL of 1.4-1.69 defines a predominantly sedentary person. ${ }^{26}$ Moderate activity was defined as the time spent in activities between 3 and 5.9 metabolic equivalents (METs), such as brisk walking, sweeping floors, and vacuuming. ${ }^{27}$ Vigorous activities were defined as physical activity performed at an intensity above 6 METs, such as jogging, shovelling, or carrying heavy loads. ${ }^{27}$

Steps per day and time spent in moderate intense physical activities were regarded as co-primary endpoints since these parameters contain information on both the amount of daily activity and intensity. Average movement intensity during walking, total walking time per day, total active time per day, vigorous activities, and PAL were used as secondary outcomes.

Data were collected from June 2010 to July 2012, covering all yearly seasons. 


\begin{tabular}{|c|c|c|c|}
\hline & & Mean (SD) & Range \\
\hline \multirow[t]{4}{*}{ Demographics } & Age (years) & $62(9)$ & $41-80$ \\
\hline & Gender (female/male) & $26 / 25$ & \\
\hline & Height $(\mathrm{cm})$ & $169(9)$ & $153-198$ \\
\hline & Body mass index $\left(\mathrm{kg} / \mathrm{m}^{2}\right)$ & $27.4(5.0)$ & $19.9-40.4$ \\
\hline \multirow[t]{5}{*}{ Lung function } & $\mathrm{FEV}_{1}(\mathrm{~L})$ & $2.02(0.58)$ & $1.07-3.25$ \\
\hline & $\mathrm{FEV}_{1}(\%$ of predicted) & $74(14)$ & $51-113$ \\
\hline & GOLD I-II (n) & \multicolumn{2}{|l|}{$\begin{array}{l}13-38 \\
(25 \%-75 \%)\end{array}$} \\
\hline & $\mathrm{FEV}_{1} / \mathrm{FVC}$ & $57(9)$ & $31-69.9$ \\
\hline & Years of diagnosis COPD & \multicolumn{2}{|c|}{$\begin{array}{l}<1 \text { year: } 30 \% \\
1-5 \text { years: } 52 \% \\
>5-10 \text { years: } 16 \% \\
>10 \text { years: } 2 \%\end{array}$} \\
\hline \multicolumn{4}{|c|}{$\begin{array}{l}\mathrm{COPD}=\text { chronic obstructive pulmonary disease, } F E V_{1}=\text { forced expiratory volume } \\
\text { in one second, } F \mathrm{VC}=\text { forced vital capacity, } \mathrm{GOLD}=\mathrm{Global} \text { initiative for } \\
\text { chronic Obstructive Lung Disease. }\end{array}$} \\
\hline
\end{tabular}

\section{Statistical analyses}

Baseline characteristics are reported as mean \pm standard deviation (SD) and range for continuous variables and as number (\%) for categorical variables. The relationship between variables was tested by calculating Pearson correlation coefficients and plots. Correlation coefficients were considered to be statistically significant when the $p$ value was $<0.05$. All data were analysed using SPSS Version 19.

\section{Results}

\section{Characteristics}

The clinical characteristics of the COPD patients are presented in Table 1. The age spectrum of participants varied from relatively young COPD patients up to rather old patients. There was an almost equal distribution of men and women and they generally had an overweight body mass index (BMI). Patients had a mean $\mathrm{FEV}_{1}$ of $74 \%$ predicted, indicating moderate COPD (close to mild COPD). The majority of patients were recently diagnosed as having COPD.

There was a large variation in the extent of dyspnoea experienced, as indicated by the MRC score (Table 2). Some participants were only breathless during strenuous exercise while others were hardly able to walk more than 100 meters or capable of leaving the house.

Functional exercise capacity was close to what might be expected for healthy persons (Table 2). In addition, the lowest oxygen saturation during the 6MWT was $83 \%$ while the mean (SD) value was $92 \%$ (3.4\%). Twenty-one percent of the patients had an oxygen saturation below $90 \%$ during the test, indicating a significant decrease in oxygenation during exertion. ${ }^{28}$ The resting oxygen saturation had a mean (SD) value of $96 \%(1.5 \%)$ with a range of 92-99\%.

Patients were classified as sedentary with a mean PAL of 1.45 and only $65 \%$ of the recommended 10,000 steps per day (Table 2).

\section{Functional exercise capacity, pulmonary function,} and clinical characteristics

A significant inverse correlation was found between 6MWD (\% predicted) and MRC ( $R=-0.43, p=0.001)$. There was no correlation

\begin{tabular}{|c|c|c|c|}
\hline & & Mean (SD) & Range \\
\hline $\begin{array}{l}\text { Patient-reported } \\
\text { outcomes }\end{array}$ & $\begin{array}{l}\text { MRC dyspnoea } \\
\text { scale }\end{array}$ & $2.5(0.9)$ & $1-5$ \\
\hline \multirow[t]{3}{*}{$\begin{array}{l}\text { Exercise } \\
\text { capacity }\end{array}$} & $\begin{array}{l}\text { 6-minute walk } \\
\text { distance (metres) }\end{array}$ & $487(86)$ & $320-650$ \\
\hline & $\begin{array}{l}\text { 6-minute walk } \\
\text { distance (\% of } \\
\text { predicted) }\end{array}$ & $94(14)$ & $60-121$ \\
\hline & $\begin{array}{l}\text { Lowest oxygen } \\
\text { saturation during } \\
6 \text {-minute walk } \\
\text { test (\%) }\end{array}$ & $92(3.4)$ & $83-98$ \\
\hline \multirow[t]{7}{*}{ Physical activity } & Steps per day & $6,459(2,994)$ & $1,853-1,5437$ \\
\hline & $\begin{array}{l}\text { Movement intensity } \\
\text { during walking }(\mathrm{g})\end{array}$ & $0.20(0.039)$ & $0.15-0.40$ \\
\hline & $\begin{array}{l}\text { Time spent walking } \\
\text { per day }\end{array}$ & $1: 19(0: 32) \mathrm{hrs}$ & $0: 25-2: 38 \mathrm{hrs}$ \\
\hline & Total active time & $5: 20(1: 42) \mathrm{hrs}$ & 1:34-9:39 hrs \\
\hline & $\begin{array}{l}\text { Time in moderate } \\
\text { physical activity }\end{array}$ & $1: 37(0: 35) \mathrm{hrs}$ & 0:34-3:30 hrs \\
\hline & $\begin{array}{l}\text { Time in vigorous } \\
\text { physical activity }\end{array}$ & $0: 9(0: 13)$ hrs & $0: 1: 10 \mathrm{hrs}$ \\
\hline & Physical activity level & $1.45(0.12)$ & $1.21-1.88$ \\
\hline
\end{tabular}

observed between 6MWD (\% predicted) and $\mathrm{FEV}_{1}$ (\% predicted), age, and BMI.

\section{Daily physical activity, pulmonary function, and clinical characteristics}

A significant modest inverse correlation was found between steps per day, PAL, total walking time per day, time spent in moderate physical activity, and $B M I(R=-0.32, p=0.022 ; R=-0.42, p=0.003$; $R=-0.38, p=0.006 ; R=-0.29, p=0.038$; respectively). There were also significant modest inverse correlations between steps per day, PAL, total walking time per day, total active time, time spent in moderate physical activity, and the MRC dyspnoea scale $(R=-0.35, p=0.012$; $R=-0.34, p=0.019 ; R=-0.35, p=0.011 ; R=-0.36, p=0.010 ; R=-0.29$ ， $\mathrm{p}=0.037$; respectively).

No correlation was observed between any of the physical activity variables and $\mathrm{FEV}_{1}$ (\% predicted).

\section{Functional exercise capacity and daily physical activity} No significant correlations were observed between 6MWD (\% predicted) and any of the physical activity variables (Table 3).

Figure 1 illustrates the minimal relation between 6MWD and steps per day. For example, subjects with a normal functional exercise capacity display a broad range of steps per day, varying from 3,000 up to 15,000 steps per day.

As expected, different physical activity variables were related. A high correlation was found between steps per day and time spent in moderate physical activity $(R=0.79, p=0.000)$. A more modest correlation was found between steps per day and time spent in vigorous physical activity ( $R=0.54, p=0.000)$. On the other hand, no correlation was observed between time spent in moderate physical activity and vigorous physical activity $(R=0.076, p=0.59)$. 


\begin{tabular}{|c|c|c|}
\hline & \multicolumn{2}{|c|}{ 6MWD (\% predicted) } \\
\hline & $\mathrm{R}$ & p Value \\
\hline Steps per day & 0.22 & 0.12 \\
\hline Movement intensity during walking & 0.17 & 0.23 \\
\hline Total active time & 0.23 & 0.10 \\
\hline Time spent walking & 0.21 & 0.14 \\
\hline Physical activity level & 0.24 & 0.091 \\
\hline Time in moderate physical activity & 0.21 & 0.13 \\
\hline Time in vigorous physical activity & 0.12 & 0.40 \\
\hline
\end{tabular}

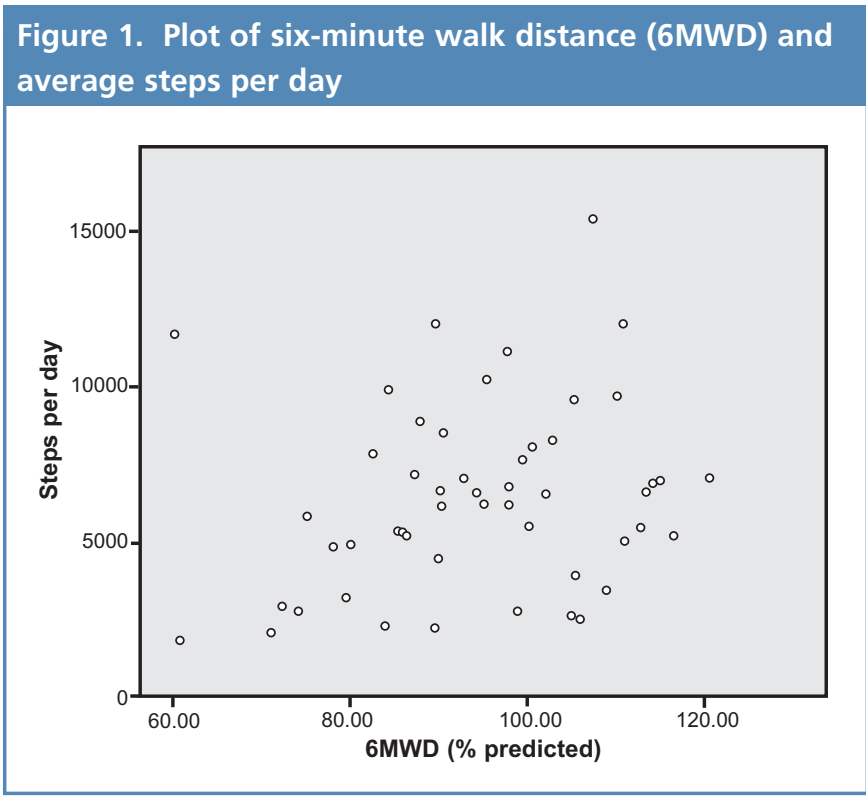

\section{Discussion}

\section{Main findings}

In this cross-sectional study we found a minimal relationship between functional exercise capacity and daily physical activity in patients with mild and moderate COPD in a primary care setting. Baseline characteristics showed that functional exercise capacity was close to normal values ( $94 \%$ of predicted). Despite the reasonable distance walked on the 6MWT, a substantial group of subjects showed a significant decrease in oxygenation during exertion. The primary causes of hypoxaemia with exertion are considered to be ventilation to perfusion mismatching and diffusion-type limitation, ${ }^{28}$ so a substantial part of our study population showed pulmonary constraints. On the other hand, daily physical activity was diminished. A mean PAL of 1.45 indicates a very sedentary population ${ }^{26}$ and a mean of 6,459 steps per day is characterised as 'low active'. ${ }^{29}$

\section{Strengths and limitations of the study}

To our knowledge, this is one of the first studies in which COPD patients were recruited and assessed solely in the primary care setting. It was our purpose to make a direct link with current COPD care in the Netherlands by using not very restrictive inclusion criteria that are congruous with daily practice. This is reflected by the large variation in all baseline characteristics, from breathlessness to exercise capacity and physical activity.

There are several limitations that need to be addressed. First, the number of assessment days plays an important role. There is evidence that three days of assessment with an activity monitor provides an acceptable intraclass reliability coefficient. ${ }^{30}$ In healthy adults, however, an acceptable measurement may range from three to seven days. It is possible that, in our study population, three days of measurement was not sufficient to collect representative data. Second, we included only patients who were motivated to participate in an exercise training programme and excluded patients who were already very active. Our conclusions cannot therefore, our conclusions cannot be generalised to all patients with mild to moderate COPD.

\section{Interpretation of findings in relation to previously published work}

The absolute value on the 6MWT of our study population (487 metres) is comparable with results of other studies in patients with mild and moderate COPD (490 and 462 metres). ${ }^{8,31}$ On the other hand, our results concerning daily physical activity differ from the findings of Troosters et al. and Watz et al. who found a mean of 7,357 and 7,619 steps per day in patients with COPD Global initiative for chronic Obstructive Lung Disease (GOLD) stages I and II, respectively, and a PAL of 1.63 compared with 6,459 steps per day and a PAL of 1.45 in our study. ${ }^{7.8}$ In the study by Watz et al. the measurement period did not include the winter months. ${ }^{8}$ This could explain the difference with our results, because it is known that seasonal variations affect physical activity patterns. ${ }^{32}$ Furthermore, the southern part of the Netherlands is known as a region with less physical activity than the rest of the country.

We found a mean duration of time spent at moderate physical activity of 1:37 hrs, which is much shorter than a mean time of 2:40 hrs (above 2.5 METs) and 2:49 hrs in age-matched controls. ${ }^{7.8}$

The main result in our study was the minimal relationship between functional exercise capacity and daily physical activity. A previously published study with a similar study population found a higher correlation between functional exercise capacity and physical activity. ${ }^{31}$ This might be explained by their inclusion of patients with severe COPD, since it has been shown that this relationship is stronger in this patient category. ${ }^{6,8,14,16}$ This is in accordance with our hypothesis that patients with better preserved lung function and exercise capacity do have a choice to be physically active or not. In patients with severe COPD, limited exercise capacity constitutes a barrier to being physically active.

To date, there is no single parameter which reflects overall daily physical activity best, so all studies concerning physical activity in COPD patients have used several different parameters. In our study we specifically collected many different walking-related physical activity parameters because functional exercise capacity was also measured by a walking test. We assumed that, if there was a correlation between these concepts, it would come forward by correlating these variables. Interestingly, these variables did not show a significant correlation at all.

The choice of the reference value on the 6MWT might have 
played a role in the correlation analysis. We used the reference value of Enright and Sherrill because of the study population, testing protocol, and the shorter length of the corridor used. ${ }^{21}$ For completeness, we also performed analyses with another reference value. $^{34}$ As a result, the mean (SD) distance walked was 76 (11.2)\% predicted and there were significant correlations between 6MWD and physical activity variables, but the correlations were only weak, ranging from $R=0.29, p=0.042$ to $R=0.31, p=0.028$. Thus, even if we had chosen to use other reference values, the overall conclusion would be a poor relationship between functional exercise capacity and daily physical activity.

\section{Implications for future research, policy and practice}

Environmental and personal factors were beyond the scope of this study. For future research it might be useful to gain more insight into these factors so that causes for physical inactivity can be explored.

The present study reinforces the idea that, although $\mathrm{FEV}_{1}, \mathrm{MRC}$ dyspnoea scale and even functional exercise capacity might be important outcomes to indicate the severity of the disease (as in the BODE index ${ }^{35}$ ), daily physical activity provides a supplementary concept, especially in patients with mild to moderate COPD. We suggest that there are actually four concepts that could be considered to describe the consequences of COPD in a broader perspective: pulmonary function (reflecting pathology), dyspnoea (reflecting symptoms), exercise capacity (reflecting ability), and physical activity (reflecting actual function).

According to our results, we could consider behavioural change with regard to daily physical activity as an important treatment goal in primary care, as functional exercise capacity was not significantly decreased and physical activity was clearly diminished. This is in line with the suggestion of Egan et al. who proposed a two-tiered approach whereby programmes in secondary care should focus on functional capacity and those in primary care should focus on physical activity. ${ }^{13}$ We want to refine this statement because in primary care there is also a substantial group of patients who could benefit from enhancing exercise capacity. Consequently, measuring daily physical activity is an essential part of the assessment in primary care in order to fine-tune treatment. It enables practitioners and physiotherapists to deliver personalised care. This is illustrated in Figure 1. Patients in the lower right quadrant have a normal to good functional exercise capacity whereas their daily physical activity is below normal values. In these patients the focus of treatment should be on improving physical activity behaviour. Patients in the lower left part of the plot might benefit from increasing both functional exercise capacity and daily physical activity, patients in the upper right quadrant are doing well and should only be encouraged to continue their current approach, and the focus of treatment of patients in the upper left quadrant might be on enhancing functional exercise capacity and finding a balance between load and load-bearing capacity.

\section{Conclusions}

The results of this study show a discrepancy between functional exercise capacity and daily physical activity in patients with mild to moderate COPD recruited and assessed in primary care. These results reinforce the importance of measuring daily physical activity in order to fine-tune treatment.

\section{Handling editor David Bellamy Statistical review Gopal Netuveli}

Acknowledgements The authors thank Daniel Langer and Hans Van Remoortel (from the Faculty of Kinesiology and Rehabilitation Sciences, KU Leuven, Belgium) for their valuable help in analysing the data. We would also like to thank all participating patients, general practices, and physiotherapy practices for their involvement in the study.

Conflicts of interest All authors declare that they have no financial or personal relationships with other people or organisations that have influenced the current work. OCPvS is an Assistant editor of the PCRJ, but was not involved in the editorial review of, nor the decision to publish, this article.

Contributorship AF substantially contributed to the design of the study, recruitment of general practices, physiotherapy practices and patients, data acquisition and analysis, and drafting the manuscript. OvS, RG and JM were involved in the design of the study, drafting the manuscript, and revising it critically. KA made contributions to acquisition and analysis of data and has been involved in revising the manuscript. All authors read and approved the final manuscript.

Funding Funding of this study is provided by the MUMC MOVE programme of Maastricht University.

\section{References}

1. Fabbri LM, Rabe KF. From COPD to chronic systemic inflammatory syndrome? Lancet 2007;370:797-9. http://dx.doi.org/10.1016/S0140-6736(07)61383-X

2. Lacasse $Y$, Martin S, Lasserson TJ, Goldstein RS. Meta-analysis of respiratory rehabilitation in chronic obstructive pulmonary disease. A Cochrane systematic review. Eura Medicophys 2007:43(4):475-85.

3. Larson JL. Functional performance and physical activity in chronic obstructive pulmonary disease: theoretical perspectives. COPD 2007;4(3):237-42 http://dx.doi.org/10.1080/15412550701480372

4. Thompson PD, Buchner D, Pina IL, et al. Exercise and physical activity in the prevention and treatment of atherosclerotic cardiovascular disease: a statement from the Council on Clinical Cardiology (Subcommittee on Exercise, Rehabilitation, and Prevention) and the Council on Nutrition, Physical Activity, and Metabolism (Subcommittee on Physical Activity). Circulation 2003;107(24):3109-16. http://dx.doi.org/10.1161/01.CIR.0000075572.40158.77

5. Zuwallack RL. How do we increase activity and participation in our patients? Semin Respir Crit Care Med 2009;30(6):708-12

http://dx.doi.org/10.1055/s-0029-1242640

6. Pitta F, Troosters T, Spruit MA, Probst VS, Decramer M, Gosselink R. Characteristics of physical activities in daily life in chronic obstructive pulmonary disease. Am J Respir Crit Care Med 2005;171(9):972-7. http://dx.doi.org/10.1164/rccm.200407-8550C

7. Troosters $T$, Sciurba $F$, Battaglia $S$, et al. Physical inactivity in patients with COPD, a controlled multi-center pilot study. Respir Med 2010;104(7):1005-11. http://dx.doi.org/10.1016/.rmed.2010.01.012

8. Watz H, Waschki B, Meyer T, Magnussen H. Physical activity in patients with COPD Eur Respir J 2009;33(2):262-72. http://dx.doi.org/10.1183/09031936.00024608

9. Waschki B, Kirsten A, Holz O, et al. Physical activity is the strongest predictor of allcause mortality in patients with COPD: a prospective cohort study. Chest 2011;140(2):331-42. http://dx.doi.org/10.1378/chest.10-2521

10. Watz $H$, Waschki B, Boehme $C$, Claussen M, Meyer T, Magnussen H. Extrapulmonary effects of chronic obstructive pulmonary disease on physical activity: a cross-sectional study. Am J Respir Crit Care Med 2008;177(7):743-51. http://dx.doi.org/10.1164/rccm.200707-10110C

11. Garcia Aymerich J, Lange P, Benet M, Schnohr P, Anto JM. Regular physical activity reduces hospital admission and mortality in chronic obstructive pulmonary disease: a population based cohort study. Thorax 2006;61(9):772-8. http://dx.doi.org/10.1136/thx.2006.060145

12. Cindy Ng LW, Mackney J, Jenkins S, Hill K. Does exercise training change physical activity in people with COPD? A systematic review and meta-analysis. Chron Respir Dis 2012;9(1):17-26. http://dx.doi.org/10.1177/1479972311430335

13. Egan $C$, Deering BM, Blake $C$, et al. Short term and long term effects of pulmonary rehabilitation on physical activity in COPD. Respir Med 2012;106(12):1671-9. http://dx.doi.org/10.1016/j.rmed.2012.08.016

14. Mador MJ, Patel AN, Nadler J. Effects of pulmonary rehabilitation on activity levels in patients with chronic obstructive pulmonary disease. J Cardiopulm Rehabil Prev 
2011;31(1):52-9. http://dx.doi.org/10.1097/HCR.0b013e3181ebf2ef

15. Probst VS, Kovelis D, Hernandes NA, Camillo CA, Cavalheri V, Pitta F. Effects of 2 exercise training programs on physical activity in daily life in patients with COPD. Respir Care 2011;56(11):1799-807. http://dx.doi.org/10.4187/respcare.01110

16. Zwerink M, van der Palen J, van der Valk P, Brusse Keizer M, Effing T. Relationship between daily physical activity and exercise capacity in patients with COPD. Respir Med 2013;107(2):242-8. http://dx.doi.org/10.1016/j.rmed.2012.09.018

17. Belza B, Steele BG, Hunziker J, Lakshminaryan S, Holt L, Buchner DM. Correlates of physical activity in chronic obstructive pulmonary disease. Nurs Res 2001;50(4):195202. http://dx.doi.org/10.1097/00006199-200107000-00003

18. Steele BG, Holt L, Belza B, Ferris S, Lakshminaryan S, Buchner DM. Quantitating physical activity in COPD using a triaxial accelerometer. Chest 2000;117(5):1359-67. http://dx.doi.org/10.1378/chest.117.5.1359

19. Steuten LM, Creutzberg EC, Vrijhoef HJ, Wouters EF. COPD as a multicomponent disease: inventory of dyspnoea, underweight, obesity and fat free mass depletion in primary care. Prim Care Respir J 2006;15(2):84-91. http://dx.doi.org/10.1016/j.pcrj.2005.09.001

20. Miller MR, Hankinson J, Brusasco V, et al. Standardisation of spirometry. Eur Respir J 2005;26(2):319-38. http://dx.doi.org/10.1183/09031936.05.00034805

21. Enright PL, Sherrill DL. Reference equations for the six-minute walk in healthy adults. Am J Respir Crit Care Med 1998;158(5 Pt 1):1384-7. http://dx.doi.org/10.1164/ajrccm.158.5.9710086

22. ATS statement: guidelines for the six-minute walk test. Am J Respir Crit Care Med 2002;166(1):111-17. http://dx.doi.org/10.1164/ajrccm.166.1.at1102

23. Bestall JC, Paul EA, Garrod R, Garnham R, Jones PW, Wedzicha JA. Usefulness of the Medical Research Council (MRC) dyspnoea scale as a measure of disability in patients with chronic obstructive pulmonary disease. Thorax 1999;54(7):581-6. http://dx.doi.org/10.1136/thx.54.7.581

24. Van Remoortel $H$, Raste $Y$, Louvaris Z, et al. Validity of six activity monitors in chronic obstructive pulmonary disease: a comparison with indirect calorimetry. PLOS One 2012;7(6):e39198. http://dx.doi.org/10.1371/journal.pone.0039198

25. Hunter GR, Larson Meyer DE, Sirikul B, Newcomer BR. Muscle metabolic function and free-living physical activity. J Appl Physiol 2006;101(5):1356-61. http://dx.doi.org/10.1152/japplphysiol.01160.2005

26. Black AE, Coward WA, Cole TJ, Prentice AM. Human energy expenditure in affluent societies: an analysis of 574 doubly-labelled water measurements. Eur J Clin Nutr 1996;50(2):72-92.

27. Ainsworth BE, Haskell WL, Whitt MC, et al. Compendium of physical activities: an update of activity codes and MET intensities. Med Sci Sports Exerc 2000;32(9 Suppl):S498-504. http://dx.doi.org/10.1097/00005768-200009001-00009

28. Panos RJ, Eschenbacher W. Exertional desaturation in patients with chronic obstructive pulmonary disease. COPD 2009;6(6):478-87. http://dx.doi.org/10.3109/15412550903341497

29. Tudor Locke C, Bassett DR, Jr. How many steps/day are enough? Preliminary pedometer indices for public health. Sports Med 2004;34(1):1-8. http://dx.doi.org/10.2165/00007256-200434010-00001

30. Pitta F, Troosters T, Probst VS, Spruit MA, Decramer M, Gosselink R. Quantifying physical activity in daily life with questionnaires and motion sensors in COPD. Eur Respir J 2006;27(5):1040-55. http://dx.doi.org/10.1183/09031936.06.00064105

31. Eliason $G$, Zakrisson AB, Piehl Aulin K, Hurtig Wennlof A. Physical activity patterns in patients in different stages of chronic obstructive pulmonary disease. COPD 2012;8(5):369-74. http://dx.doi.org/10.3109/15412555.2011.605403

32. Levin S, Jacobs DR, Jr., Ainsworth BE, Richardson MT, Leon AS. Intra-individual variation and estimates of usual physical activity. Ann Epidemiol 1999;9(8):481-8. http://dx.doi.org/10.1016/\$1047-2797(99)00022-8

33. Harbers. Lichamelijke activiteit: Zijn er binnen Nederland verschillen naar regio? Volksgezondheid Toekomst Verkenning, Nationaal Kompas Volksgezondheid. Bilthoven: RIVM, 2010.

34. Troosters T, Gosselink R, Decramer M. Six minute walking distance in healthy elderly subjects. Eur Respir J 1999;14(2):270-4. http://dx.doi.org/10.1034/j.1399-3003.1999.14b06.x

35. Celli BR, Cote CG, Marin JM, et al. The body-mass index, airflow obstruction, dyspnea, and exercise capacity index in chronic obstructive pulmonary disease. $\mathrm{N}$ Engl J Med 2004;350(10):1005-12. http://dx.doi.org/10.1056/NEJMoa021322

\section{Available online at http://www.thepcrj.org}

